\title{
Festival Kugoma 2020 (Maputo, Moçambique)
}

\section{Inês Cordeiro Dias}

University of Leeds, School of Languages, Cultures and Societies

i.cordeirodias@leeds.ac.uk

https://orcid.org/0000-0002-1808-4199

O Festival Kugoma ${ }^{1}$ realizou este ano a sua $11^{\text {a }}$ edição, de 24 a 30 de Agosto de 2020. Criado por Diana Manhiça e Ilda Abdala, o Kugoma exibe principalmente curtas-metragens realizadas nos Países Africanos de Língua Oficial Portuguesa (PALOPs), em outros países da Lusofonia e em países africanos não-lusófonos. Segundo Diana Manhiça ${ }^{2}$, que ainda hoje é a curadora e foi até 2019 também a produtora, a criação do festival partiu do desejo de levar o cinema aos bairros periféricos de Maputo. Entre 2007 e 2009, Diana Manhiça, Ilda Abdala e Ivan Laranjeira organizaram um cineclube nas salas de cinema do centro da capital, com duas sessões por semana. No entanto, percebendo que o público se reduzia às elites das artes e aos expatriados, decidiram criar um festival e levá-lo aos bairros periféricos, de maneira a criar novos públicos, principalmente junto dos jovens, oferecendo conteúdos africanos, em português e de qualidade. Pensado como um festival que complementasse a oferta existente (por exemplo, com o já extinto DocKanema), surgiu a ideia de criar um festival de curtas-metragens, e assim surge o Kugoma.

Nos primeiros anos, o festival teve sessões simultâneas nas salas de cinema de Maputo e em vários bairros da cidade. Isto implicava a existência de várias equipas, uma para cada bairro, para assegurar a projeção dos filmes. Tal foi possível graças ao apoio de instituições como o Instituto Camões e a Cooperação Espanhola, entre outros. No entanto, com mudanças políticas nos países de apoio e nas direções destas instituições, muitos destes apoios acabaram por desaparecer, o que levou a que, nos últimos anos, o festival regressasse quase em exclusivo às salas de cinema de Maputo, nomeadamente ao Cinema Scala e ao Centro Cultural Franco-Moçambicano.

\footnotetext{
${ }^{1} 0$ website oficial pode ser consultado em: www.kugoma.org (último acesso: 4 de novembro de 2020).

2 Entrevista da autora, a 25 de Outubro de 2020.
} 
No entanto, a experiência nos bairros permitiu perceber que o Kugoma era muito popular entre o público juvenil, o que levou à criação do Kugoma Escolas, que traz agora as crianças e os jovens às salas de cinema para assistirem aos filmes. Segundo Diana Manhiça, trazer as crianças às salas é mais barato e mais fácil em termos logísticos, mas continua o desejo de voltar a levar o Kugoma aos bairros periféricos - embora isso dependa de apoios financeiros que nem sempre estão disponíveis. Devido à luta constante por financiamentos, sempre escassos, Diana Manhiça nota que o Kugoma é um festival de resistência - principalmente num mundo em que as abordagens à cultura são cada vez mais focadas em obter lucros financeiros.

O festival é organizado pela Associação Museu do Cinema (tal como outros eventos, como a Semana do Cinema Africano e o UPCycles Residência Criativa Audiovisual). Em 2020, a Diana continuou responsável pela curadoria, mas a produção ficou a cargo de António Maxlhaieie, que já tinha vindo a colaborar nas edições anteriores do festival. Devido à pandemia e tal como muitos festivais pelo mundo inteiro, o Kugoma 2020 foi realizado em várias plataformas online: nas páginas de Facebook do Kugoma ${ }^{3}$, do Centro Cultural Franco-Moçambicano ${ }^{4}$ e do Centro Cultural MoçambicanoAlemão ${ }^{5}$, no YouTube, na plataforma VOD NetKanema e nos canais de televisão Televisão de Moçambique e STV Moçambique. Segundo a organização, a edição deste ano teve mais público do que nos anos anteriores, e está em aberto a possibilidade de um formato híbrido nas edições futuras, principalmente no que diz respeito aos workshops.

Na semana que precede a exibição de filmes, acontece o A Caminho do Kugoma, que dá lugar a vários debates e workshops. Este ano, o realizador moçambicano João Ribeiro dirigiu o workshop Pitch, push \& pull: como construir o dossier de um projeto audiovisual, e a brasileira Júlia Alves dirigiu Pitching: técnicas para a apresentação de projetos audiovisuais. Nos debates, Júlio Chilela e Ivandro Maocha falaram de plataformas de VOD (Video On Demand) nos PALOPs ${ }^{6}$, principalmente da angolana Tellas ${ }^{7}$ e da

\footnotetext{
${ }^{3}$ https://www.facebook.com/Kugoma (último acesso: 19 de novembro de 2020).

${ }^{4}$ https://www.facebook.com/CentroCulturalFrancoMocambicano (último acesso: 19 de novembro de 2020).

${ }^{5}$ https://www.facebook.com/ccma.goethe.maputo.de (último acesso: 19 de novembro de 2020).

${ }^{6}$ Debate disponível em: https://www.youtube.com/watch?v=rMU20bP0nek\&feature=youtu.be (último acesso: 4 de novembro de 2020).

${ }^{7}$ https://tellas.co.ao (último acesso: 4 de novembro de 2020).
} 
moçambicana NetKanema ${ }^{8}$. Estas plataformas funcionam de forma semelhante ao Netflix e a outras plataformas VOD. A Tellas disponibiliza conteúdos exclusivamente em português e a NetKanema disponibiliza cinema moçambicano, revertendo os lucros para os realizadores dos filmes. 0 segundo debate ${ }^{9}$, com a presença de Samira Vera-Cruz (Cabo Verde), Mauro Pereira (Angola), Kátya Aragão (S. Tomé) e Emília Wojcieschowska (Cabo Verde), apresentou a Rede de Cinema e Audiovisual PALOP-TL, e os cineastas falaram ainda da importância das colaborações sul-sul, como forma de contornar a dependência de financiamentos europeus, e de outros desafios que enfrentam, na distribuição e circulação dos seus filmes.

Os filmes foram divididos em oito sessões, mais duas sessões juvenis e o cine-concerto. 0 cine-concerto tem por tradição apresentar alguns filmes mudos com música composta e tocada ao vivo por músicos locais, e costuma ser um dos momentos de maior visibilidade do festival. Este ano foram apresentadas três curtas-metragens de George Méliès com música composta e musicada por Catarina Domingues (acordeão), Euclides Anatolly (guitarra) e Nelson Mondlane (percussão). 0 Kugoma criou no ano passado o primeiro prémio do festival, o Prémio do Júri - Novos Autores Moçambique, e, em 2020, acrescentou a este, o Prémio do Júri - Novos Autores PALOP-TL ${ }^{10}$. 0 prémio internacional foi para o filme Turtle Friend/ Amigo das Tartarugas (2019), de Abel Monteiro (Cabo Verde), um documentário sobre Didi, que criou o seu próprio negócio de turismo com a ajuda de outros moradores de São Pedro. Didi leva os turistas a verem as tartarugas, mas também contribui, sempre que pode, para a conservação destes animais, libertando-os, por exemplo, de plásticos, e criando uma consciência ecológica na sua comunidade.

$\mathrm{Na}$ categoria nacional, foram premiados em ex-aequo os filmes Começa a ficar tarde (2020), de Ivan Barros, e a animação Um Presente especial (2020), de Nildo Essá. Este último conta a história de um grupo de amigos que decide decorar a escola para o Natal, mas que para isso precisa de enfrentar um bully que quer estragar os seus planos. Começa a ficar tarde é um filme ensaio que reflete sobre o lixo e quem vive dele, sem qualquer tipo de diálogo, mas com uma das composições visuais mais marcantes deste

${ }^{8}$ https://netkanema.co.mz (último acesso: 4 de novembro de 2020).

${ }^{9}$ Debate disponível em: https://www.youtube.com/watch?v=rZu6QRM5nfY\&feature=youtu.be (último acesso: 4 de novembro de 2020).

${ }^{10}$ A sessão com os filmes vencedores pode ser vista em:

https://www.facebook.com/Kugoma/videos/624928138027406 (último acesso: 4 de novembro de 2020).

anikiExposições e festivais de cinema | Exhibitions and film festivals 
festival, e um dos filmes a não perder. Outro filme experimental de destaque é Treino Periférico (2020), do ator, escritor e realizador Welket Bungué, com a atriz Isabél Zuaa (que ganhou recentemente um Kikito no Festival de Gramado). 0 filme é uma reflexão filosófica e poética sobre ser-se periférico na sociedade portuguesa contemporânea, sendo Welket Bungué um dos artistas mais promissores do panorama artístico português ${ }^{11}$.

Ainda dentro do filme ensaio, quero também destacar Corpo - Objecto Humano (2020) do ator, bailarino e coreógrafo moçambicano Pak Ndjamena, que usa a performance em espaços fechados e nas ruas de Maputo, com uma máscara de gesso, refletindo sobre a relação do sujeito com estes espaços e com o outro no contexto da pandemia. Ainda no que diz respeito aos filmes experimentais, mas já no campo das longas-metragens, é também de salientar o documentário Kmêdeus (2020), de Nuno Miranda (Cabo Verde), que reflete sobre a figura lendária de um excêntrico habitante das ruas do Mindelo, que uns consideraram lunático e outros artista.

O Kugoma apresentou ainda dois documentários de longa-metragem: Terra de Todos, Terra de Alguns 12, realizado por Diogo Cardoso (Portugal/ Moçambique, 2018), que parte da investigação de Boaventura Monjane e Sofia da Palma Rodrigues sobre a desapropriação de terras no Corredor de Nacala, mostrando como os camponeses se uniram para resistir às grandes multinacionais. Uma das líderes camponesas diz que estão perante uma segunda guerra, já que as comunidades locais precisam de lutar de novo pelo seu direito à terra e cultivá-la para se alimentarem. Além do destaque para a pesquisa detalhada e para os depoimentos dos camponeses, noto ainda a qualidade da fotografia e da edição. 0 segundo documentário longo da mostra foi The Sound of Masks, de Sara Gouveia (África do Sul, Moçambique, Portugal, 2018), também com uma fotografia excepcional, que nos conta a história de Atanásio Nyusi, um bibliotecário considerado durante muitos anos o melhor bailarino de Mapiko em Maputo. Através dele descobrimos a história da dança dos Mapikos e da sua importância na cultura moçambicana, em particular na cultura makonde. Segundo Atanásio, o Mapiko tornou-se um instrumento de contestação à colonização, tendo por isso sido proibido pelo regime português.

11 O Festival CineBH realizou uma mostra de seis filmes de Welket Bungué, em outubro de 2020.

${ }^{12} \mathrm{O}$ filme inclui uma reportagem multimédia online que pode ser vista em: https://terradealguns.divergente.pt (último acesso: 4 de novembro de 2020). 
Os documentários moçambicanos curtos Nhenha (2018), de André Bahule, e A Gravidez é Nossa (2020), de Tina Krueger e David Aguacheiro, desafiam as concepções tradicionais de género. Nhena dá a conhecer um grupo de mulheres da comunidade de Nwadjahane, Mandlakazi, que usam a dança Xingomana como instrumento de emancipação. A Gravidez é Nossa traz aos ecrãs um grupo de homens de uma comunidade rural moçambicana que desafiam o papel tradicional masculino e reclamam para si o direito de cuidarem dos filhos e da casa, de igual para igual, com as suas mulheres.

Um dos maiores obstáculos enfrentados pelos jovens realizadores moçambicanos é a falta de condições financeiras para realizarem os seus filmes, sendo que tais limitações incluem muitas vezes o acesso a uma câmara de filmar. Uma das fontes de financiamento muitas vezes disponíveis é dedicada a filmes institucionais e pedagógicos, de sensibilização da população para diversos problemas locais. Por exemplo, $A$ Caminho do Lifeca (2020), de Ernanio Mandlate, trata dos problemas de saúde pública causados pela defecação a céu aberto em comunidades sem acesso a redes sanitárias. Já o filme Combate ao Corte de Árvores (2020), de Isidro Mangue, usa o tema do título para criar um curto filme de ação em que os polícias prendem os cortadores ilegais de árvores, incluindo cenas encenadas de luta entre eles, ao estilo dos filmes de "maningue porrada", o nome dado aos filmes de ação, muito populares nas salas de cinema de Maputo, sobretudo na década de 70. Outro filme feito com recursos muito limitados, mas que merece destaque pela construção narrativa, é Januário, o Engenheiro à Distância (2020), de Rupia Júnior e Milton Tinga. Um jovem tenta falar com a professora por chamada de vídeo para tirar dúvidas, mas a chamada está sempre a cair e ele acaba por ficar sem crédito. Três anos depois, vemos o jovem Januário já empregue como engenheiro e responsável pela construção de um prédio que acaba por cair, ao que o chefe da empresa reage: "Eu disse para não chamar esses jovens de 2020!"

O Kugoma é também uma importante oportunidade para a criação de redes entre os vários cineastas que nele participam, sendo este, provavelmente, o impacto mais importante do festival, como notou Diana Manhiça. É também de ressaltar a parceria com outros festivais no continente (destacando-se, por exemplo, a colaboração com o Plateau de Cabo Verde), e no cenário da Lusofonia. Dentro deste contexto, surgiu há dois anos a iniciativa Rede do Cinema e Audiovisual dos PALOPs, que pretende fazer um mapeamento preliminar de profissionais e empresas ligados ao cinema, criando uma base de dados online, bem como fortalecer a distribuição de conteúdos destes 
países, primeiro a nível regional, depois a nível lusófono e mais tarde a nível global.

O Festival Kugoma é assim um espaço essencial para o desenvolvimento de novos cineastas nos países lusófonos, e oferece aos jovens moçambicanos a oportunidade de verem filmes em português, filmes nacionais e filmes africanos de qualidade. Os prémios recentemente criados pretendem incentivar os jovens cineastas moçambicanos a apresentarem os seus filmes no festival. Muitos estudantes de cinema têm vindo a apontar o Kugoma como uma fonte de inspiração para continuarem a fazer cinema em Moçambique. Infelizmente, devido à escassez de recursos, o festival não tem capacidade de analisar o seu verdadeiro impacto junto do público local. No entanto, o festival continua a divulgar o cinema africano e lusófono junto das escolas e universidades, contribuindo assim para a criação de mais público cinematográfico no país.

\section{Filmografia}

A Caminho do Lifeca. Dir. Ernanio Mandlate. KISAI Produções EI. Moçambique, 2020, 8 min.

Combate ao Corte de Árvores. Dir. Isidro Mangue. Isidro Mangue. Moçambique, 2020, 5 min.

Começa a Ficar Tarde. Dir. Ivan Barros. Margarida Bondo, Idio Chichava, Ivan Barros, Francisco Vinagre, Isaias Uamba. Moçambique, 2020, 14 $\min$.

Corpo - Objeto Humano. Dir. Pak Ndjamena. Centro Cultural Moçambicano Alemão. Moçambique, 2020, 23 min.

A Gravidez É Nossa. Dir. Tina Krueger e David Aguacheiro. Anna Galle e Aguacheiro Multimédia. Moçambique, 2020, 15 min.

Januário - O Engenheiro à Distância. Dir. Rupia Júnior e Milton Tinga. Kadore Entretenimento \& Filmes Produtora. Moçambique, 2020, 5 min.

Kmêdeus (Comer Deus). Dir. Nuno Miranda. Negrume. Cabo Verde, 2020, 53 min.

Nhenha (Força). Dir. André Bahule. André Bahule e Karen Boswall. Moçambique, 2018, 25 min.

Terra de Todos, Terra de Alguns. Dir. Diogo Cardoso. Divergente. Portugal/Moçambique, 2018, $53 \mathrm{~min}$. 
Treino Periférico. Dir. Welket Bungué. Kussa Productions. Portugal/ GuinéBissau, 2020, 20 min.

The Sound of Masks (O Som das Máscaras). Dir. Sara Gouveia. Lionsfish Productions/ Ukbar Filmes. África do Sul/ Portugal/ Moçambique, 2018, $70 \mathrm{~min}$.

Turtle Friend (Amigo das Tartarugas). Dir. Abel Monteiro. Abel Monteiro. Cabo Verde, 2019, 8 min.

Um Presente Especial. Dir. Nildo Essá. FX Estúdios de Animação. Moçambique, 2020, 6 min. 